African Crop Science Journal by African Crop Science Society is licensed under a Creative Commons Attribution 3.0 Uganda License. Based on a work at www.ajol.info/ and www.bioline.org.br/cs DOI: http://dx.doi.org/10.4314/acsj.v25i4.7

\title{
COMBINING ABILITY AND HETEROTIC PATTERN IN WEST AFRICAN SORGHUM LANDRACES
}

\author{
E.A. AKATA ${ }^{1,3}$, C. DIATTA ${ }^{1}$, J.M. FAYE ${ }^{1,2}$, A. DIOP ${ }^{1,}$ F. MAINA ${ }^{2,6}$, B. SINE $^{1}$, W. TCHALA ${ }^{4}$, \\ I. NDOYE 5 , G.P. MORRIS ${ }^{2}$ and N. CISSE
}

${ }^{1}$ Centre d'Etude Régional pour l'Amélioration de l'Adaptation à la Sécheresse (CERAAS / ISRA), Sénégal

${ }^{2}$ Department of Agronomy, Kansas state university (KSU), USA

${ }^{3}$ Institut Togolais de Recherche Agronomique (ITRA), Togo

${ }^{4}$ Ecole Supérieure d'Agronomie, Université de Lomé (ESA/UL), Togo

${ }^{5}$ Université Cheikh Anta Diop de Dakar (UCAD), Sénégal

${ }^{6}$ Institut National de la Recherche Agronomique du Niger (INRAN) Niamey, Niger

Corresponding author: jacko9145@yahoo.com

(Received 30 July, 2017; accepted 30 October, 2017)

\begin{abstract}
Heterotic grouping based on combining ability for traits of interest, in addition to plant performance and genetic relationship among germplasm, would be useful in planning crosses in breeding programmes. This study aimed at determining the combining abilities of selected landraces for morphological and physiological traits under contrasted environments and identifying the suitable heterotic grouping method for superior hybrid production. For this purpose, nineteen accessions representing different origins and population structure among West African Sorghum Accessions Panel (WASAP) and two female lines, were used in « Line $\mathrm{x}$ tester » mating design to produce thirtyeight (38) hybrids. Analysis of variance showed significant general combining ability and specific combining ability effects for grain weight, plant height, days to flowering, panicle length and chlorophyll content implying existence of heterotic responses for these traits. Both additive and non-additive gene effects were important in controlling the inheritance of the traits. Parents K31.3, K37 and Ni331 were the best combiners for grain weight, providing the opportunity for breeders to improve grain yield under diverse environments. AVG-1 x K31.3 and AVG-1 x Tg148 were the superior hybrids. Combining ability based heterotic grouping methods classified sorghum accessions into four groups. The heterotic group's specific and general combining ability (HSGCA) method was the suitable in predicting hybrid superiority. This combining abilities based heterotic grouping study is an additional tool that breeders could use to identify the best parents for superior hybrids development in West Africa.
\end{abstract}

Key Words: Combining ability, heterotic groups, sorghum, West Africa

\section{RESUME}

La détermination des groupes hétérotiques basée sur les aptitudes à la combinaison des traits d'intérêt en plus des performances et des relations génétiques dans une collection est importante pour planifier les croisements en sélection. Cette visait la détermination des aptitudes à la combinaison des accessions locales pour certains traits morphologiques sous environnements contrastés et l'identification de la meilleure méthode dans la prédiction de la vigueur hybride. Dans cette perspective, dix-neuf accessions représentant différentes origines et la structure de la population d'un panel ouest africain de sorgho (WASAP) et deux mâles stériles ont été utilisés dans un croisement «Line $\mathrm{x}$ tester » pour produire trente-huit hybrides $\mathrm{F}_{1}$, objet de cette étude. L'analyse de variance a 
indiqué des effets significatifs de l'aptitude générale et spécifique à la combinaison pour le poids grain, la hauteur plante, la durée semis floraison et la concentration en chlorophylle traduisant l'existence des réponses hétérotiques pour ces traits. Les effets géniques additif et non-additif ont été importants dans le contrôle de ces caractères. K31.3, K37 et Ni331 présentent les meilleures aptitudes générales à la combinaison puis AVG-1 x K31.3 et AVG$1 \times$ Tg148 ont été les meilleurs hybrides pour le poids grains. Ils constituent une opportunité pour l'amélioration dans divers environnements. Les différentes méthodes ont classé les accessions de sorgho en quatre groupes. Le groupage basé sur la méthode HSGCA accroit l'efficience en sélection de $15 \%$. Cette étude offre un outil d'aide pour les sélectionneurs dans le choix des meilleurs parents à croiser pour la production des hybrides supérieurs en Afrique de l'Ouest.

Mots Clés: Afrique de l'Ouest, aptitude à la combinaison, groupe hétérotique, sorgho

\section{INTRODUCTION}

Sorghum [Sorghum bicolor (L.) Moench] is the world's fifth most important cereal grain, after wheat, maize, rice and barley in terms of production; and is largely a subsistence food crop in Africa (Taylor, 2003). Sorghum has a large genetic diversity (Billot et al., 2013), derived from farmers' selection over years, under a wide range of environments. This adaptation to diverse agriclimatic conditions is a source of favourable alleles that could be used in breeding (Morris et al., 2013).

In West Africa, despite their weak yield potential, local landraces are still largely used in sorghum production. After $70^{\text {th }}$ drought, high yielding and short maturing varieties (SEPON 82 and SRN 39) as well as promising sorghum hybrids with high yield potential (Hageen-Dura-1, NAD-1, ICSH 89002 and 89009) were introduced or/and created by research and released with the support of McKnight foundation (Murty, 2002; Olembo et al., 2010). These varieties had met a high enthusiasm at producer' levels at the time of their release and impact sorghum production in the region. However, gradually the use of these exotic new varieties (mainly Caudatum type) has declined due to their lack in local food quality requirements (Olembo et al., 2010). In addition, they did not fit with the local farming system because of their height input demand (Yapi et al., 2000; Ouédraogo, 2005). To overcome this limitation, hybrid might meet farmers' use requirements, such as grain quality, plant height and adaptation to local constraints (Kante et al., 2017). As farmers are interested to their accessions, the local landraces-based hybrids are expected to have good acceptability and good adaptation to local grow conditions in the region (Camara et al., 2006). Combining ability and Heterotic grouping studies of such germplasm, facilitates its exploitation in breeding and the choice of suitable parents for superior hybrid combinations (Akinwale et al., 2014).

Combining ability is the capacity of an individual to transmit superior performance to its offspring. It provides information on gene effects in controlling inheritance of traits of interest and helps in selecting the parents to be included in cultivar improvement or hybridization programmes. It is the best way to test the value of a germplasm and identify the best parents to produce superior hybrids (Kanawade et al., 2001; Kenga et al. 2004; Mindaye et al., 2016). As the performance of lines crossed with testers could be used as criteria for grouping the lines (Melchinger, 1999), using combining ability information for heterotic grouping of local germplasm may help to select superior hybrid parents to meet farmer's use requirements.

Heterotic grouping refers to the identification of groups that are genetically distinct from each other and that produce superior hybrids when crossed. breeders have been using morphological per se performance (Barro-Kondombo et al., 2008; Sawadogo et al., 2014) and genetic relationship (Zongo et al., 2005; Deu et al., 2006; Sagnard et al., 2011; Billot et al., 2013) method to classify 
available germplasm into distinct heterotic groups and to identify suitable parents for crosses. However, several methods using combining ability information for heterotic grouping, reported in maize, showed the usefulness of such methods in identifying suitable hybrid parents (Fan et al., 2009; BaduApraku et al., 2013; Akinwale et al., 2014). These are the specific combining ability (SCA) effects of grain yield (Melchinger and Gumber 1998; Fan et al., 2009), the heterotic group's specific and general combining ability \% HSGCA (Fan et al., 2009; Akinwale et al., 2014) and heterotic grouping based on general combining ability (GCA) of multiple traits \% HGCAMT (Badu-Apraku et al., 2013). The discovery of male sterility (Stephens and Holland, 1954) in sorghum, the key of hybrids production, gives an opportunity for heterosis exploitation to increase sorghum production. Thus, there is a need of information on combining ability based heterotic grouping, particularly in west african local sorghum accessions to help breeders when selecting parents to use in crosses. The objectives of this study were to determine the combining abilities of selected landraces for morphological and physiological traits under contrasted environments and to identify the suitable heterotic grouping method to increase hybrid breeding efficiency.

\section{MATERIALS AND METHODS}

Site characteristics. The trial was conducted in Senegal during the rainy season of 2016 (July to December) in two contrasted locations representing the main sorghum growing area in West Africa (Sahelian and Soudano-Sahelian climate). The first location was the National Centre for Agronomic Research (CNRA) in Bambey (latitude $14^{\circ} 42^{\prime} \mathrm{N}$; longitude $16^{\circ} 28^{\prime} \mathrm{W}$, altitude $17 \mathrm{~m}$ ). The climate is typical of the Sahelian zone with the average rainfall between 400 and $700 \mathrm{~mm}$ from July to October. The total rainfall during experiment period was 387 $\mathrm{mm}$. The second location was Sinthiou Maleme (latitude $12^{\circ} 47^{\prime} \mathrm{N}$; longitude $15^{\circ} 33^{\prime} \mathrm{W}$, altitude
$30 \mathrm{~m}$ ) research station of Senegalese agronomic research institute (ISRA). This station is in Soudano-Sahelian zone with the average rainfall between 800 to $1000 \mathrm{~mm}$ from June to October. The total rainfall during the period of the experiment was of $548 \mathrm{~mm}$.

Parental lines and hybrids development. The experiment involved 19 male parents and two cytoplasmic male sterile lines as female parents, along with their 38 hybrids and three checks. The male parents belonged to West African Sorghum Association Panel (WASAP) from four countries (Niger, Mali, Senegal and Togo). They were selected to represent the different origins involved in this panel and the population structures based on SNPs markers (Fig. 1). The characteristics of selected genotypes are presented in Table 1. The female parents were CE 310-31A (CK612A x CE31125B) and AVG-1. These 21 parents (19 males and two females) were crossed according to the line $\mathrm{x}$ tester mating design developed by Kempthorne (1957), during the rainy season of 2015 at CNRA in Senegal. In order to synchronize flowering of the male and female parents, all the 21 parents were planted three times, with 10 days intervals. Thirty-eight $F_{1}$ hybrids were obtained from the crosses between the male and female parents. A total of sixty-three genotypes, comprising of hybrids, their parents and four checks were used in this study. The check varieties included two hybrids (AVG-1A x DORADO and CE 310-31A x NGANDA), one local improved line (IRAT204) and one Guinea Senegalese landrace (53-49).

Field experiments and data collection. The 63 sorghum entries were arranged in a $9 \times 7$ lattice design, with three replications at each location. Each genotype was planted in one row of $5 \mathrm{~m}$ long, with $40 \mathrm{~cm}$ between hills, giving 13 hills per row and an inter-row spacing of $80 \mathrm{~cm}$. The experiments were handplanted and, ten days after planting, all rows were thinned to three plants per hill; resulting in a population of about 93,750 plants per ha. 


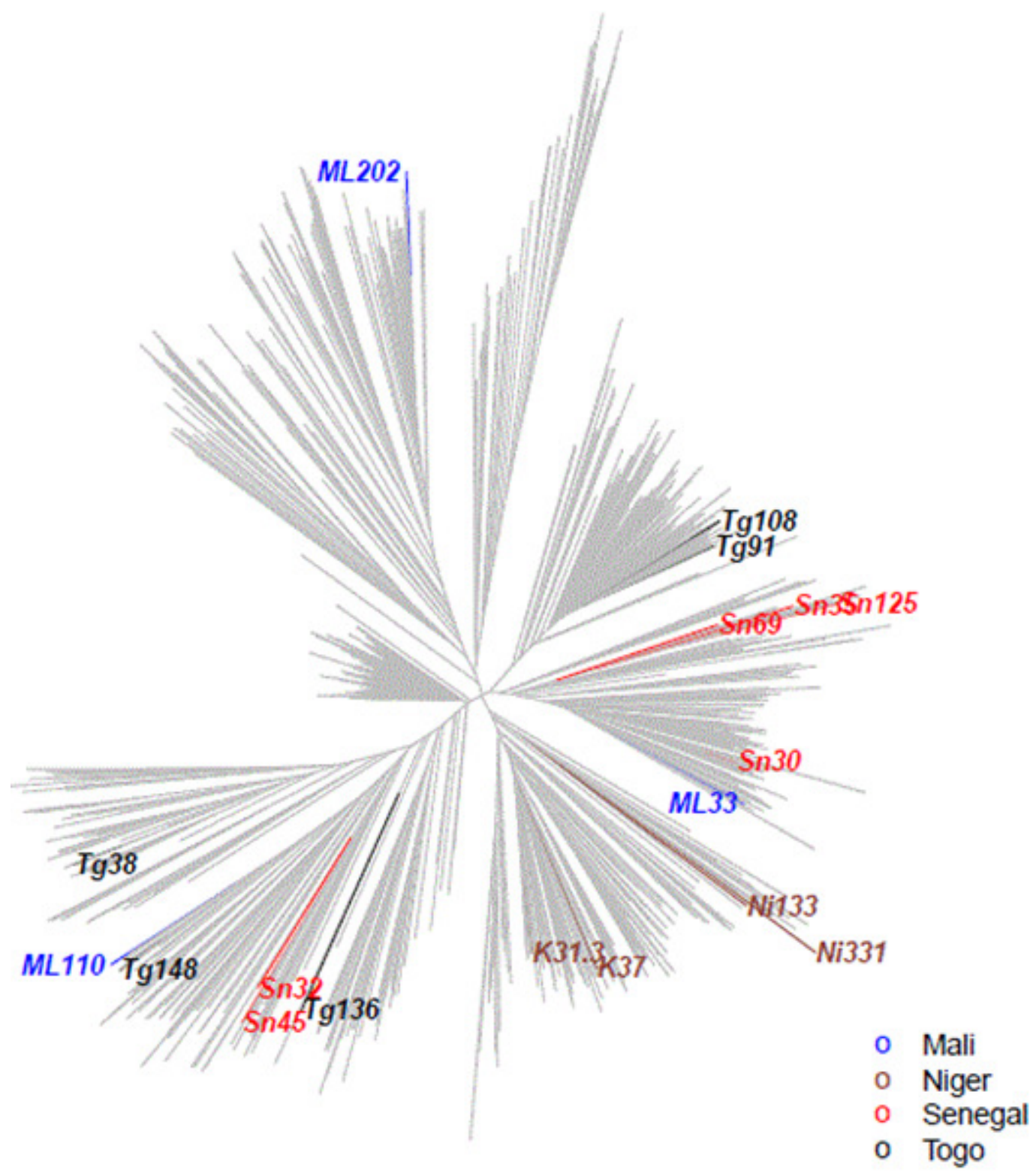

Figure 1. Neighbour joining unrooted tree based on 1500 SNPs markers of 757 West African sorghum association panel (WASAP) showing population structure. Highlighted are eighteen (18) accessions from Mali (ML), Niger (Ni and $\mathrm{K})$, Senegal (Sn) and Togo (Tg) used in this study.

Fertiliser NPK (15-15-15) was applied at the dose of $150 \mathrm{~kg} \mathrm{ha}^{-1}$ at each location before sowing. One hundred $\mathrm{kg} \mathrm{ha}^{-1}$ of urea, subdivided into two sub-doses of $50 \mathrm{~kg} \mathrm{ha}^{-1}$ was applied two times, 30 and 45 days after planting. Weeding was done manually.

Six quantitative traits, namely four morphological and two physiological characters, were measured. Morphological traits such as number of days to flowering, plant height, panicle length and grain weight were recorded according to the International Board for Plant Genetic Resources (IBPGR) and ICRISAT descriptor list for sorghum (IBPGR/ICRISAT, 1993). Chlorophyll content and leaf temperature were recorded on the 
TABLE 1. Description of the 19 West African sorghum accessions and two male steriles used in this study

\begin{tabular}{lllll}
\hline Accession & Local Cod & Origin & Race & Genotype \\
\hline ML110 & Nioro3 & Mali & Caudatum & landrace \\
ML202 & SMIL-147 & Mali & Guinea & landrace \\
ML33 & O9-SB-Caract-1097 & Mali & Guinea & landrace \\
Ni133 & S402 & Niger & Durra-Caudatum & landrace \\
Ni206 & K31-3 & Niger & Durra-Caudatum & landrace \\
Ni216 & K37 & Niger & Durra-Caudatum & landrace \\
Ni331 & SSD 35 & Niger & Guinea & landrace \\
Sn125 & 198 SSM964 D & Senegal & Guinea & landrace \\
Sn30 & 5349 & Senegal & Guinea & landrace \\
Sn32 & Rassoulou & Senegal & Guinea & landrace \\
Sn35 & Samba Souko SD 3 & Senegal & Guinea & landrace \\
Sn45 & Wan Bassi & Senegal & Guinea & landrace \\
Sn69 & Samba souki SD6 & Senegal & Guinea & landrace \\
Tg108 & TGVL 108 & Togo & Guinea & landrace \\
Tg136 & TGVL 136 & Togo & Guinea-Caudatum & landrace \\
Tg148 & TGVL 148 & Togo & Caudatum & landrace \\
Tg164 & Sorvato1 & Togo & Caudatum & improved line \\
Tg38 & TGVL 38 & Togo & Caudatum & landrace \\
Tg91 & TGVL 91 & Togo & Guinea & landrace \\
CE 310-31A/B & - & Senegal & Caudatum & Improved line \\
A/BVG-1 & - & USA & Caudatum & Improved line \\
\hline
\end{tabular}

physiologically active young leaf (third, from top to bottom) at midday on the $30^{\text {th }}$ day after planting. Leaf temperature was recorded by an infrared thermometer (Quicktemp 860-T2 Testo AG) and chlorophyll content was measured using SPAD chlorophyll content meter (SPAD-502, Konica Minolta). Number of days to flowering was assessed on a whole plot basis. Plant height, panicle length, chlorophyll content and leaf temperature were taken on five central randomly selected plants of each plot. At maturity, panicles of the five central selected plants were cut, sun-dried, threshed and weighed to determine the grain weight per plant.

Genotyping-by-sequencing (GBS). Punch leaf disks were sampled from eight weeks old plants in the field and dried in a stove at $40^{\circ}$ during three days. DNA was extracted following a Mixed Alkyl Trimethyl Ammonium Bromide (MATAB) method (Frost et al., 2007) at Centre d'Etude Régional pour l'Amélioration de l'Adaptation à la Sécheresse (CERAAS) and sent to Morris Laboratory at Kansas State University in USA for genotyping. GBS libraries were prepared and analysed as described by Elshire et al. (2011), using the enzyme ApeKI for digestion. This was followed by the ligation of the adapters to the digested DNA. Each sample has unique identifiers, which are the barcoded adapter located upstream and the common adapter downstream of the digested DNA. The ligated DNA from each 96-well plate was then pooled in a $1.5 \mathrm{ml}$ tube to obtain a 96-plex library. The PCR was done using the forward and reverse primers from the adapters and amplified products were purified (using QIA quick PCR purification kit, Qiagen) before the determination of sample size. For each step, quality control was performed to verify if samples were digested, ligated and amplified using agarose gel, picogreen and nanodrop. The library size (in base pairs) was obtained using the bioanalyzer and single-end read sequences were obtained using Illumina HiSeq2500 100-cycle at University of Kansas 
Medical Center, USA. Sequences data obtained were processed with the GBS v2 pipeline implemented in TASSEL 5 (Glaubitz et al., 2014). The filtered sequences were aligned to the sorghum reference genome BTx623 (Sorghum bicolor v.1.0). After filtering for missing data, minor allele frequency, linkage disequilibrium pruning and thinning, 1500 SNPs covering all the ten chromosomes of the sorghum genome were retained and used to assess population structure.

Data analysis. The analysis of variance (ANOVA) was performed for each location to test homogeneity. Then, the checks were removed and data of all locations were combined and rearranged according to line $\mathrm{x}$ tester design as outlined by Singh and Chaudhary (1985). The analysis of variance and the estimation of combining ability were performed using R-package "plantbreeding" (Rosyara, 2014) under R software Version 3.2.3. The Sum of Squares for hybrids was further partitioned into variation due to lines (GCAl), testers (GCAt) and line $\mathrm{x}$ tester interactions (SCA). Estimates of GCA variances $\left(\sigma_{\mathrm{GCA}}^{2}\right)$ and SCA variances $\left(\sigma_{\mathrm{SCA}}^{2}\right)$ were obtained as suggested by Singh and Chaudhary (1977). Ratios of Mean Square Components associated with variance of GCA and SCA effects were computed as suggested by Baker (1978) to estimate the relative importance of GCA in explaining performance. The closer the ratio is to unity, the greater the predictability of progeny performance based on GCA effects alone. Standard errors for GCA and the SCA effects were calculated using the method described by Cox and Frey (1984). The significance of the GCA and SCA effects were tested by calculating " $t$ " value using the formula of Cox and Frey (1984) as follow:

- t-test for GCA effects:

$t=\frac{G C A}{S E G C A l}, \quad$ where, SEGCAl $=\sqrt{\frac{M S E}{r t s}}$
$t=\frac{G C A}{\text { SEGCAt }}, \quad$ where, SEGCAt $=\sqrt{\frac{M S E}{r l s}}$

Where:

$S E G C A l$ and $S E G C A t=$ standard error for $G C A$ line and tester, $\mathrm{r}=$ number of replication, $l=$ line number, $t=$ tester number, $s=$ number of location, $M S E=$ mean square of error.

- t-test for SCA effects:

$t=\frac{S C A}{S E S C A^{\prime}} \quad$ where, $S E S C A=\sqrt{\frac{M S E}{r s}}$

Where:

$S E S C A=$ standard error of $S C A, M S E=$ mean square of error, $r=$ number of replication and $s=$ number of site.

Heterotic grouping. Four heterotic grouping methods were used to assign male parents into different groups, including SCA effects for grain yield (Pswarayi and Vivek 2004; Menkir et al., 2004), heterotic group's specific and general combining ability (HSGCA) of the grain yield (Fan et al., 2009), heterotic grouping based on GCA of multiple traits (HGCAMT) method proposed by Badu-Apraku et al. (2013) and genetic distance from SNPs markers.

As two female lines (CE 310-31A and AVG1) were used in this study, the principle of SCA effects method is as follows: Germplasm showing positive SCA effects with CE 310$31 \mathrm{~A}$ and exhibiting negative SCA effects with AVG-1 were classified into heterotic Group 1. Genotypes showing positive SCA effects with AVG-1 and negative effects with CE 310-31A were assigned into heterotic Group 2. Similarly, accessions showing positive SCA effects with both testers were placed under heterotic Group 3. Likewise, the individuals exhibiting negative SCA effects with both testers were 
kept under a Group 4. The HSGCA method was used as follows:

HSGCA = Cross mean Xij-Tester mean $X i=$ $G C A t+S C A$

Where:

$X i j$ is the mean yield of the cross between the $i t h$ tester and the $j$ th line, $X i$. is the mean yield of the $i t h$ tester.

The calculated HSGCA effects for grain yield were used in three steps to classify the 19 sorghum accessions into heterotic groups. At the first step, all accessions with negative HSGCA effects were placed into the same heterotic groups. At this step, certain genotypes were classified into more than one heterotic group. At the second step, accessions assigned to more than one heterotic group in step 1 , were kept in the heterotic group corresponding to the smallest value of HSGCA (or largest negative value) and thus removed it from other heterotic groups. At the third step, accessions with a positive HSGCA effect with all the testers, was assigned to any positive HSGCA heterotic group.

Grouping by the HGCAMT method was achieved by a dendrogram using Ward's method based on Euclidean distances obtained from GCA effects of all traits.

Population structure based on neighbor joining tree using 1500 SNPs markers (Fig. 1) was constructed to be used mainly as background information to select male parents and to calculate breeding efficiency for heterotic groups identified for comparison with other methods. The R-package "ape" was used for this analysis.

\section{RESULTS}

Analysis of variance. The Mean Squares for genotypes $(\mathrm{G})$ and environments (E) were significant for all measured traits (Table 2). Partitioning of the genotypes into components revealed that GCA (lines and testers) and SCA mean squares were significant for all measured traits except the leaf temperature. The mean square for $\mathrm{G} \times \mathrm{E}$ interaction, was significant for all traits except leaf temperature. The mean square of GCA $x$ E interaction was significant for days to flowering (both lines and testers), plant height and chlorophyll content (lines). The mean square of SCA $x$ E interaction was significant for all traits. In all cases, the mean squares of GCA effects were larger than those of the SCA for all traits except chlorophyll content and leaf temperature. The variance component estimates of SCA were greater than those of GCA for days to 50\% flowering, plant height, panicle length, chlorophyll content, leaf temperature and grain weight (Table 2). Furthermore, the ratio of the mean square components associated with variance of GCA and SCA was much less than the theoretical maximum of unity for all traits studied.

\section{Combining ability estimates}

General combining ability. The general combining ability effect of testers for all measured traits are presented in Table 3. Significant positive and negative GCA effects were observed for all traits, except leaf temperature. Lines K31.3, Ni331 and K37 recorded significant and positive GCA effects for grain weight. In contrast, Tg91, Sn69, Sn35, Tg108 and Sn125 recorded negative GCA effects for the same trait. For days to flowering, testers Ni331, Ml33, Sn32, M1110, Tg148 and Sn69 exhibited significant and negative GCA effects. In contrast, $\mathrm{Tg} 91$, Tg108, Sn45, M1202 and Tg38 recorded significant and positive for the same trait. For plant height, Sn30, Sn45 and K31.3 recorded significant and positive values; while $\operatorname{Sn} 125$, Tg148, Tg108 and Sorvato1 exhibited negative GCA effects. For panicle length, K31.3, K37 and $\mathrm{Sn} 30$ are good combiners. For chlorophyll content, Tg136 recorded positive GCA effect and $\operatorname{Tg} 148$ the negative one.

Specific combining ability. The specific combining ability effects of crosses for 
TABLE 2. Mean squares derived from the combined analysis of variance for morphological traits of 38 hybrids along their parents evaluated at Bambey and Sinthiou in Senegal

\begin{tabular}{|c|c|c|c|c|c|c|c|}
\hline Source of variation & Df & DFLo & $\mathrm{PH}(\mathrm{cm})$ & $\mathrm{PL}(\mathrm{cm})$ & GrW (g) & (SPAD) & $\operatorname{LT}\left({ }^{\circ} \mathrm{C}\right)$ \\
\hline Env. (E) & 1 & $304.53 * * *$ & $254234.13 * * *$ & $393.47 * * *$ & $117835.58 * * *$ & $5480.49 * * *$ & $116,58 * * *$ \\
\hline Gen. (G) & 37 & $384.12 * * *$ & $16668.99 * * *$ & $128.86 * * *$ & $4607.28 * * *$ & $20.84 * * *$ & 3,47 \\
\hline $\mathrm{GCA} l$ & 1 & $843.34 * * *$ & $67804.01 * * *$ & $112.73 * *$ & $6837.27 * *$ & $72.53 * *$ & 7,69 \\
\hline $\mathrm{GCA} t$ & 18 & $589.04 * * *$ & $22863.88 * * *$ & $210.24 * * *$ & $6941.74 * * *$ & $15.46^{*}$ & 2,44 \\
\hline SCA & 18 & $153.69 * * *$ & $7633.26^{* * *}$ & $48.38 * * *$ & $2148.94 * *$ & $23.35 * * *$ & 4,25 \\
\hline $\mathrm{G}^{*} \mathrm{E}$ & 37 & $21.85^{* * *}$ & $3848.44 * * *$ & $21.63^{* *}$ & $2305.28 * * *$ & $16.37 * *$ & 2,72 \\
\hline $\mathrm{GCA} l \times \mathrm{E}$ & 1 & $85.35 * *$ & 94.13 & 3.82 & 870.26 & 0.06 & 1,65 \\
\hline $\mathrm{GCA} t \times \mathrm{E}$ & 18 & $25.35 * * *$ & $3030.15^{* * *}$ & 14.3 & 2870.33 & $15.12 *$ & 3,92 \\
\hline $\mathrm{SCA} \times \mathrm{E}$ & 18 & $14.82 *$ & $4875.31 * * *$ & $29.96 * *$ & $1819.96 * *$ & $18.52 * *$ & 1,59 \\
\hline Error & 148 & 8.6 & 1090.89 & 12.76 & 909.49 & 9.03 & 2,66 \\
\hline \multicolumn{8}{|c|}{ Variance component estimates } \\
\hline Line & & 24.34 & 2111.33 & 2.26 & 164.51 & 1.73 & 0.12 \\
\hline Tester & & 144.94 & 5076.8 & 53.95 & 1597.64 & -2.62 & -0.6 \\
\hline$\sigma_{\mathrm{GCA}}^{2}$ & & 10.87 & 426.56 & 3.8 & 116.1 & 0.12 & 0.04 \\
\hline$\sigma_{\text {SCA }}^{\text {GCA }}$ & & 96.21 & 4095.99 & 25.52 & 931 & 2.48 & 1.51 \\
\hline$\sigma_{\mathrm{GCA}}^{2} / \sigma_{\mathrm{SCA}}^{2}$ & & 0.11 & 0.10 & 0.15 & 0.12 & 0.05 & 0.03 \\
\hline \multicolumn{8}{|c|}{ Proportional contribution to total variance } \\
\hline Line & & 5.97 & 10.99 & 2.36 & 4.01 & 9.41 & 6 \\
\hline Tester & & 74.58 & 66.73 & 79.37 & 73.3 & 36.11 & 34.27 \\
\hline Line $\mathrm{x}$ tester & & 19.45 & 22.28 & 18.27 & 22.69 & 54.48 & 59.73 \\
\hline
\end{tabular}

*, significant at 0.05 probability level; **, significant at 0.01 level; ***, highly significant; DFLo $=$ days to $50 \%$ flowering; $\mathrm{PH}=$ plant height $; \mathrm{SPAD}=$ leaf chlorophyll content $; \mathrm{LT}=$ leaf temperature; $\mathrm{PL}=$ panicle length and $\mathrm{GrW}=$ grain weight $/$ panicle

measured traits are presented in Table 4. For days to 50\% flowering, hybrids CE310-31A $x$ Sn32, CE310-31A x Tg148, AVG-1 x Tg148, AVG-1 x Ni331, AVG-1 x Sn32, AVG-1 x Sn69 and AVG-1 x ML33, exhibited highly significant negative SCA effects. In contrary, the hybrids CE310-31 A x Sn45, CE310-31 A x Tg91, AVG-1 x Sn45, AVG-1 xTg91, could be adapted to long cropping season zones. Hybrids CE310-31A x Sn30, CE310-31A x Sn45, CE310-31A x Tg136 and AVG-1 x ML33, with the highest significant positive SCA effects were the tallest; while CE310-31A x Sn125, CE310-31A x Tg108, AVG-1 x Sn125, AVG-1 x Tg108 and AVG-1 x Tg148 exhibited negative SCA effect for this trait.
For grain weight, hybrids with high yield and significant positive SCA effects were obtained in combinations CE310-31A x ML202, CE310-31A x Sn32, CE310-31A x K37, AVG1A x ML33, AVG-1 x Tg148, AVG-1 x K31.3 and AVG-1 $x$ K37. For panicle length, the best combinations were CE310-31A x Sn30, CE310-31A x K37, CE310-31A x K31.3, AVG1 x Sn30, AVG-1 x K37, AVG-1 x ML33, with positive SCA effects. For chlorophyll content, significant SCA effects were found for combinations between CE310-31A and ML202, Sn32, Sn45, Tg148 and Tg164. Hybrid CE310-31A x Tg164 showed positive effects; while CE310-31A x Tg148, CE31031A x ML202 and CE310-31A x Sn45 exhibited negative effects. 
TABLE 3. Estimates of general combining ability (GCA) effects of 19 lines (West african local adapted sorghum) and 2 testers for morphological and physiological traits

\begin{tabular}{|c|c|c|c|c|c|c|}
\hline Parental line & DFLo & $\mathrm{PH}(\mathrm{cm})$ & SPAD & LT $\left({ }^{\circ} \mathrm{C}\right)$ & PL (cm) & GrW (g) \\
\hline \multicolumn{7}{|l|}{ Tester } \\
\hline CE310-10B & -1.93 & -17.24 & 0.56 & 0.18 & -0.70 & -5.48 \\
\hline AVG-1B & 1.93 & 17.24 & -0.56 & -0.18 & 0.70 & 5.48 \\
\hline \multicolumn{7}{|l|}{ Line } \\
\hline Ni331 & $-8.74 * * *$ & 13.93 & 0.65 & 0.12 & -1.72 & $36.83 * *$ \\
\hline Ni133 & -2.45 & 22.86 & -0.52 & -0.52 & -2.50 & 14.04 \\
\hline $\mathrm{Ni} 206$ & 1.51 & $46.01^{*}$ & 0.04 & -0.80 & $9.47 * * *$ & $37.50 * *$ \\
\hline Ni216 & -1.83 & 27.60 & -0.28 & -0.15 & $8.91 * * *$ & $35.30 * *$ \\
\hline ML110 & $-6.07 * * *$ & 1.29 & 0.34 & -0.22 & -2.47 & 21.67 \\
\hline ML33 & $-7.57 * * *$ & -17.07 & -0.83 & -0.27 & $3.58^{*}$ & -12.06 \\
\hline ML202 & $4.38 * *$ & 30.71 & -0.64 & -0.04 & $-3.78^{*}$ & -21.11 \\
\hline Sn32 & $-6.82 * * *$ & 2.81 & 1.55 & -1.13 & -1.89 & 8.97 \\
\hline Sn30 & 1.01 & $59.32 * *$ & -1.17 & -0.10 & $7.05 * * *$ & 9.61 \\
\hline Sn45 & $6.92 * * *$ & $51.79 * *$ & -0.66 & 0.28 & $-2.77 *$ & -5.31 \\
\hline Sn69 & $-3.66 * *$ & -18.09 & -0.32 & 0.38 & -0.56 & $-32.09 * *$ \\
\hline Sn125 & -2.33 & $-81.53 * * *$ & 0.56 & 0.51 & $-3.64 *$ & $-24.39 *$ \\
\hline Sn35 & -1.49 & -19.32 & 0.98 & -0.05 & -2.35 & $-30.32 *$ \\
\hline $\operatorname{Tg} 108$ & $6.08 * * *$ & $-69.26 * * *$ & 0.67 & 0.15 & -2.18 & $-26.33^{*}$ \\
\hline Tg91 & $22.13 * * *$ & 25.79 & -0.15 & 0.54 & -2.63 & $-36.024 * *$ \\
\hline $\operatorname{Tg} 136$ & 1.51 & 37.21 & $1.98 *$ & 0.42 & 1.55 & 4.83 \\
\hline $\operatorname{Tg} 148$ & $-4.32 * *$ & $-77.06 * * *$ & $-2.70 * * *$ & 0.46 & -0.97 & -5.73 \\
\hline Tg38 & $3.58 *$ & 16.38 & -1.12 & 0.15 & $-2.91 *$ & 7.43 \\
\hline $\operatorname{Tg} 164$ & -1.83 & $-53.38 * *$ & 1.63 & 0.29 & -0.18 & 17.19 \\
\hline
\end{tabular}

*, significant at 0.05 probability level; **, significant at 0.01 level; ***, highly significant; DFLo $=$ days to $50 \%$ flowering; $\mathrm{PH}=$ plant height; $\mathrm{SPAD}=$ leaf chlorophyll content; $\mathrm{LT}=$ leaf temperature; $\mathrm{PL}=$ panicle length and $\mathrm{GrW}=$ grain weight $/$ panicle

Per se performance and combining ability. Closed correlations $(\mathrm{r}=1)$ were observed between parents per se performance and general combining ability for grain weight (Fig. 2). In addition, significant and positive correlation was observed between GCA of grain weight and panicle length $(\mathrm{r}=0.52$, $\mathrm{P}<0.05)$ and negative with leaf temperature $(\mathrm{r}=$ $-0.47, \mathrm{P}<0.05)$. Genotypes with good GCA for grain weight showed poor GCA for leaf temperature. Hybrid per se performance was found closely correlated to specific combining ability of all traits (Fig. 2). For grain weight, relative hybrid superiority was found to be correlated to general combining ability $(\mathrm{r}=$ $0.65, \mathrm{P}<0.0001$ ), to specific combining ability $(\mathrm{r}=0.69, \mathrm{P}<0.0001)$ and closely to hybrid per se performance $(\mathrm{r}=0.94, \mathrm{P}<0.0001)$.
Heterotic groups and relative hybrid superiority. The SCA effects of grain yield method classified sorghum accessions into four heterotic groups (Table 5). Accessions of Group 1 had non-significant GCA for grain weight; while Group 2 and 4 are poor combiners for the same trait. Genotypes of Group 3 were good combiners for grain weight.

The HSGCA method assigned accessions to four heterotic groups of 5, 3, 5 and 6 genotypes (Table 5). This method classified together in Group1, late flowering and negative GCA of grain weight accessions. Genotypes of Group 2 were good combiners for grain weight and earliness. Group 3 comprised of good combiners for grain weight and nonsignificant GCA for flowering time. Accessions 
TABLE 4. Estimates of specific combining ability (SCA) effects of 38 hibrids from line (19 West african local adapted sorghum) $\mathrm{x}$ testers (2) for morphological and physiological traits

\begin{tabular}{|c|c|c|c|c|c|c|}
\hline Hybrid cross & DFLo & $\mathrm{PH}(\mathrm{cm})$ & SPAD & $\mathrm{LT}\left({ }^{\circ} \mathrm{C}\right)$ & PL (cm) & $\mathrm{GrW}(\mathrm{g})$ \\
\hline \multicolumn{7}{|l|}{ CE310-31A $x$} \\
\hline Ni331 & 0.68 & 9.77 & 4.52 & 0.56 & 1.26 & 0.61 \\
\hline ML202 & 3.18 & $53.29 * *$ & $-7.03 * *$ & 0.86 & -1.41 & $34.66^{*}$ \\
\hline Sn32 & $-29.53 * * *$ & -25.62 & $5.34 *$ & -2.62 & 0.22 & $38.96^{*}$ \\
\hline Sn30 & $5.92 * *$ & $146.60 * * *$ & $6.62 *$ & -0.65 & $8.28 * * *$ & 25.34 \\
\hline $\operatorname{Sn} 45$ & $10.76 * * *$ & $121.48^{* * *}$ & $-6.84 *$ & 0.45 & -1.67 & -21.44 \\
\hline Sn69 & 1.22 & $-65.65^{* *}$ & 0.89 & 0.86 & $4.92 *$ & $-39.04 *$ \\
\hline Sn125 & -3.91 & $-109.67 * * *$ & 1.43 & 0.32 & $-11.43^{* * *}$ & $-53.70 * *$ \\
\hline Sn35 & 2.51 & $-57.11^{*}$ & 2.11 & 0.00 & $-6.87 * * *$ & -19.67 \\
\hline $\operatorname{Tg} 108$ & 0.93 & $-83.48 * * *$ & -2.42 & 1.99 & -2.09 & -32.22 \\
\hline Tg91 & $19.26 * * *$ & 19.02 & -3.19 & 0.06 & 2.65 & $-42.52 *$ \\
\hline $\operatorname{Tg} 136$ & $4.09 *$ & $126.85^{* * *}$ & 4.40 & -0.73 & $6.67 * *$ & $3457 *$ \\
\hline $\operatorname{Tg} 148$ & $-8.65 * * *$ & -0.47 & $-9.52 * * *$ & 0.27 & 0.16 & 0.34 \\
\hline Tg38 & 2.93 & 5.83 & -1.07 & -1.03 & -2.69 & $33.67 *$ \\
\hline $\operatorname{Tg} 164$ & $-5.32 * *$ & $-55.14 *$ & $9.09 * *$ & 0.40 & 3.37 & 13.91 \\
\hline Ni133 & -3.00 & -15.78 & -4.14 & -0.84 & $-12.43 * * *$ & $-33.03 *$ \\
\hline $\mathrm{Ni} 206$ & $10.34 * * *$ & $52.79 *$ & 0.18 & 0.18 & $1.67 * * *$ & 11.53 \\
\hline $\mathrm{Ni} 216$ & $-5.94 * *$ & -1.00 & 0.75 & 0.21 & $11.59 * * *$ & $47.73 * *$ \\
\hline ML110 & $-4.40 *$ & $-59.33^{*}$ & 1.97 & 0.06 & $-9.96 * * *$ & 4.67 \\
\hline ML33 & -1.24 & $-62.36^{* *}$ & -3.73 & 0.00 & -2.24 & -3.37 \\
\hline
\end{tabular}

\section{AVG-1A $x$}

\begin{tabular}{lccrccc} 
Ni331 & $-6.96^{* * *}$ & -18.70 & -2.19 & 0.08 & -0.48 & 22.19 \\
ML202 & 0.99 & $96.7^{* * *}$ & 1.19 & -1.05 & -1.64 & -20.23 \\
Sn32 & $-7.76^{* * *}$ & -31.77 & -2.84 & -0.61 & -2.92 & 10.18 \\
Sn30 & -3.18 & 32.73 & -3.66 & -0.16 & $9.71^{* * *}$ & -7.82 \\
Sn45 & $13.65^{* * *}$ & 21.56 & -0.35 & -0.32 & -1.98 & $-43.19^{*}$ \\
Sn69 & $-7.59^{* * *}$ & -39.41 & -1.23 & 1.22 & $-13.01 * * *$ & $-76.69^{* * *}$ \\
Sn125 & $7.16^{* * *}$ & $-82.29 * * *$ & 0.68 & 1.07 & -2.29 & $-52.06^{* *}$ \\
Sn35 & $-2.30^{*}$ & $4.83^{*}$ & 4.75 & 0.47 & 2.39 & -7.81 \\
Tg108 & $17.07^{* * *}$ & $-117.16^{* * *}$ & 4.33 & 0.00 & $-7.42^{* * *}$ & $-39.02^{*}$ \\
Tg91 & $21.73^{* * *}$ & $-1.13^{*}$ & 4.57 & 0.36 & $-4.56^{*}$ & 7.89 \\
Tg136 & 2.74 & $48.42^{*}$ & 0.47 & 1.12 & 2.42 & 30.81 \\
Tg148 & $-28.22^{* * *}$ & $-110.18^{* * *}$ & -2.33 & 0.00 & 2.70 & $50.55^{* *}$ \\
Tg38 & $7.07^{* * *}$ & $66.78^{* *}$ & -1.97 & 0.45 & -3.73 & -17.91 \\
Tg164 & -0.09 & -14.62 & -3.59 & 0.00 & -0.63 & -4.15 \\
Ni133 & -1.76 & -12.11 & 2.54 & 0.75 & $-10.95 * * *$ & -11.70 \\
Ni206 & $6.32^{*}$ & $55.00^{*}$ & 1.32 & 0.00 & $6.15^{* *}$ & $53.87 * *$ \\
Ni216 & $4.73^{*}$ & 22.69 & -3.67 & 0.66 & $11.91^{* *}$ & $35.01 *$ \\
ML110 & $-15.68^{* * *}$ & $-4918^{*}$ & 3.06 & -0.68 & 0.74 & $34.36^{*}$ \\
ML33 & $-7.92^{* * *}$ & $127.86^{* * *}$ & -1.08 & -1.32 & $13.60^{* * *}$ & $35.74 *$ \\
\hline
\end{tabular}

*, significant at 0.05 probability level; **, significant at 0.01 level; ***, highly significant; DFLo $=$ days to $50 \%$ flowering; $\mathrm{PH}=$ plant height $; \mathrm{SPAD}=$ leaf chlorophyll content $\mathrm{LT}=$ leaf temperature $\mathrm{PL}=$ panicle length and $\mathrm{GrW}=$ grain weight $/$ panicle 


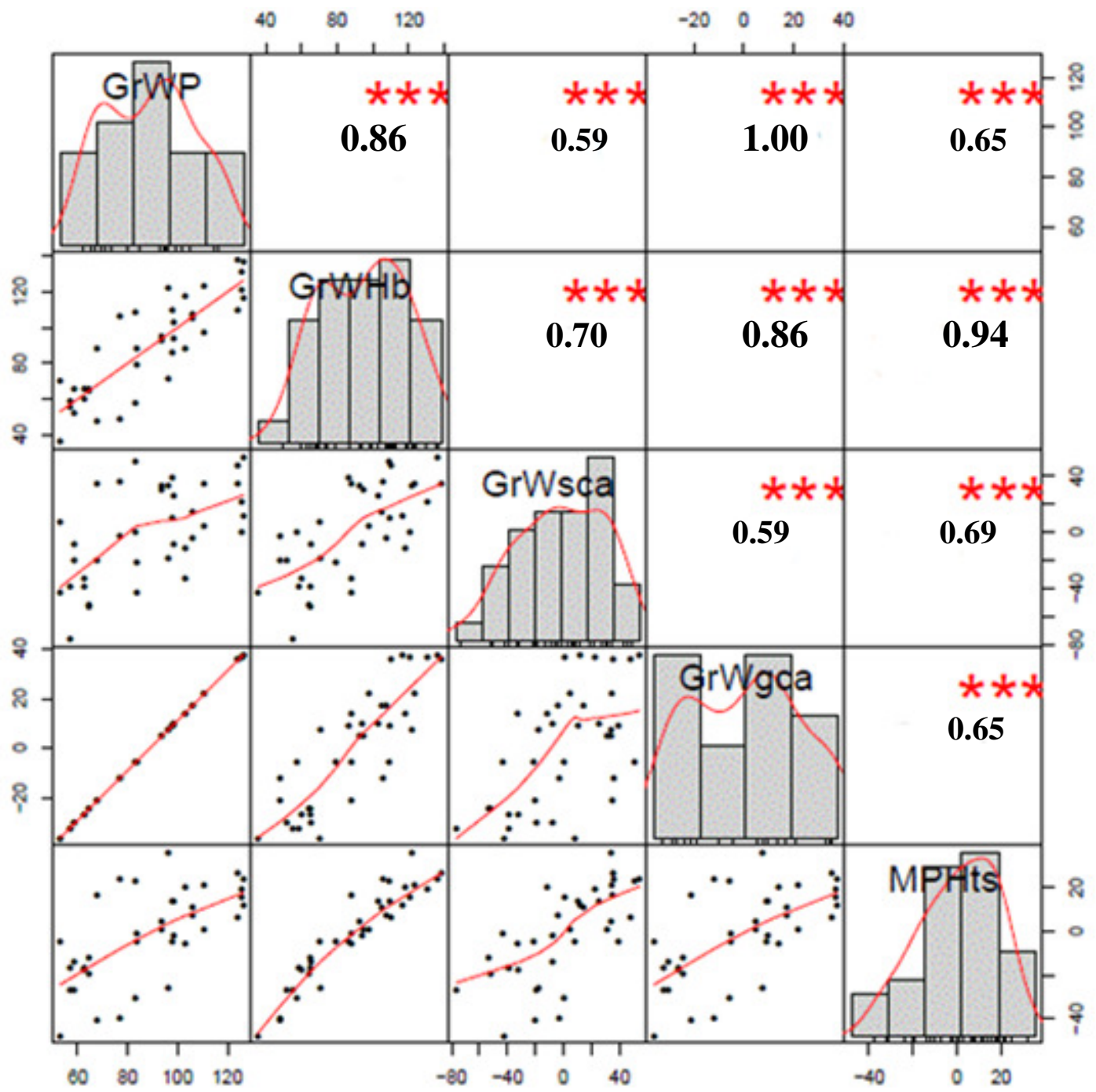

Figure 2. Per se performance and combining ability in predicting hybrid superiority for grain weight. Close relationship between line per se performance and general combining ability. Strong correlation between general and specific combining ability, hybrid per se performance and hybrid superiority for grain weight. GrWP = grain weight of lines; GrWHb = hybrid per se performance of grain weight; GrWsca = specific combining ability of grain weight; GrWgca = general combining ability of grain weight and MPHts = relative hybrid superiority over mid-parents.

of Group 4 had non-significant effects for both flowering time and grain weight.

Dendrogram based on HGCAMT method grouped sorghum accessions into four heterotic clusters (Fig. 3). Germplasm of Group 1 had negative significant GCA effect for grain weight and flowering time; while Group 2 individuals were lateness accessions. Group 3 was earliness and non-significant
GCA effects for grain weight and plant height. Group 4 was tallest and high yielding combiners.

$\mathrm{NJ}$ tree showed population structure with seven cluster reflecting mainly geographic origin and racial group (Fig. 1). There was no significant heterosis for all traits, although some hybrids showed relative superiority over mid-parent performance. For grain weight, the 
TABLE 5. Heterotic groups of 19 West African sorghum accessions identified by SCA of grain weight and HSGCA methods under two contrasted environments in Senegal

\begin{tabular}{lllll}
\hline Method & $\begin{array}{l}\text { G1: positive SCA } \\
\text { with CE310-31A }\end{array}$ & $\begin{array}{l}\text { G2: positive SCA } \\
\text { with AVG-1 }\end{array}$ & $\begin{array}{l}\text { G3: positive SCA } \\
\text { with both }\end{array}$ & $\begin{array}{l}\text { G4: negative SCA } \\
\text { with both }\end{array}$ \\
\hline SCA effects & ML202 & Tg91 & Sn32 & Ni133 \\
& Tg38 & Tg148 & Tg136 & Sn125 \\
& Tg164 & ML33 & K37 & Sn35 \\
& Sn30 & & K31.3 & Sn45 \\
& & & Ni331 & Tg108 \\
HSGCA effects & G1: negative HSGCA & G2: positive HSGCA & G3: positive & G4: negative \\
& with CE310-31A & with CE310-31A & HSGCA with AVG-1 & HSGCA with \\
& & & & CE310-31A \\
& & & ML110 & Ni133 \\
ML202 & Ni331 & Sn32 & Sn35 \\
Tg38 & K31.3 & K37 & Sn125 \\
Sn69 & ML110 & Tg164 & Tg91 \\
Tg108 & & Sn30 & ML33 \\
\hline
\end{tabular}

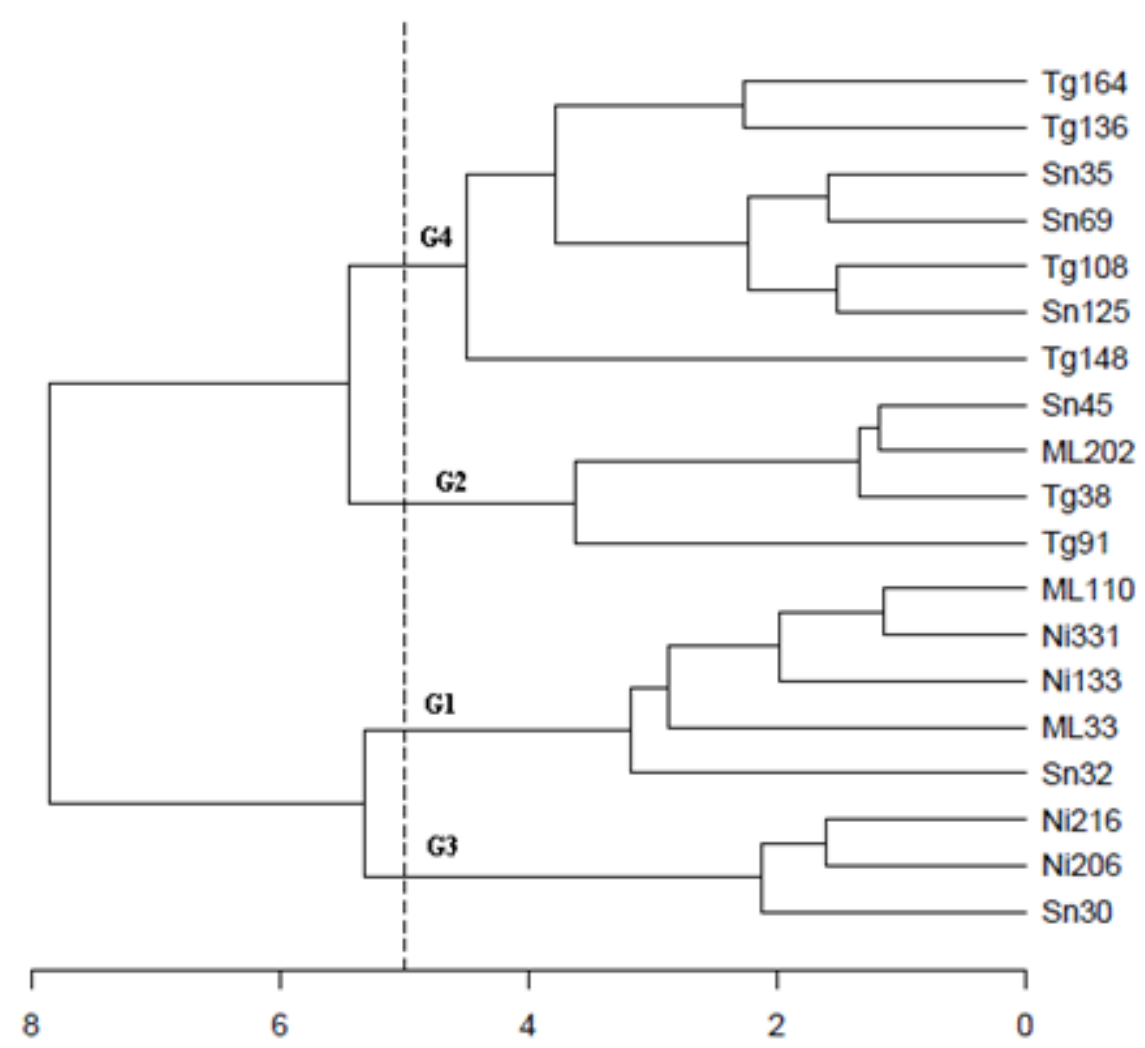

Figure 3. Dendrogram of 19 West African sorghum accession based on HGCASMT values using Ward's minimum variance cluster analysis under two contrasted environments in Senegal. GCA=general combining ability. 
highest value (35.64\%) was observed for hybrid CE310-31A x Tg38, followed by AVG$1 \mathrm{~A} \times \mathrm{K} 37(26.59 \%)$ and AVG-1A x ML33 $(23.5 \%)$. In terms of breeding efficiency, the average hybrid superiority for grain weight varied from $2 \%$ for SCA to $15 \%$ for heterotic group's specific and general combining ability method. Based on genomic population structure, hybrid superiority observed was of $14 \%$ and for heterotic grouping based on GCA of multiple traits method, $13 \%$ of yield increase was observed.

\section{DISCUSSION}

Combining ability and traits inheritance control In the present study, significant Mean Squares were found for $\mathrm{G}, \mathrm{E}$, and $\mathrm{G} \times \mathrm{E}$ interactions (Table 2) for all measured traits, except for leaf temperature, highlighting the difference between environments. Furthermore, our results indicate the existence of heterotic responses for these traits among West African sorghum accessions. This result indicated that genotypes show difference in their response to each environment. Whether hybridization or population improvement programmes, good progress could be expected using this germplasm (Kenga et al., 2004; Akinwale et al., 2014). In addition, significant interactions found between the environment and both GCA and SCA infer that their rankings changed across different environments and, therefore, selection would be more effective when based on performance under specific environments (Parviz et al., 2016).

The significant GCA and SCA mean squares observed for measured traits showed that both additive and non-additive gene actions were important in the inheritance of the traits. This suggests that significant breeding progress could be achieved using both inbreeding and hybridization. The importance of source of variation is indicated by the relative magnitude of variance components. Higher magnitude of SCA variances found for all traits studied, depicted the relative predominance of non- additive gene effects in the inheritance of these traits. These results were in agreement with findings of Kenga et al. (2004) reporting on prevalence of non-additive variance for days to anthesis, plant height, inflorescence length and grain yield per plant. Contrary to our study, earlier works have reported that additive gene effects were a predominant factor determining grain yield in sorghum (Beil and Atkins, 1967; Kirby and Atkins, 1968). The previous studies used breeding lines or previously characterized genotypes with known behaviour in cross. In this study, we used local accessions randomly selected with all wild genes. The difference could be due to plant materials used as suggested by Kenga et al. (2004) using local released genotypes and sorghum mutants.

The general combining ability (GCA) of a parent is an important indicator of its potential to provide superior lines. Both positive and negative effects of GCA were observed for all traits (Table 3). For days to flowering, in the context of short cropping season, early maturing genotypes are needed to escape terminal drought stress. However, this trait must be assessed in the context of agroecologic zone (Kenga et al., 2005). Accessions Ni331, ML33, Sn45 and Tg148 were found to be early maturing gene sources. This trait could be introgressed into preferred germplasm to select for short cropping season zones. On the other hand, genotypes with positive GCA could be used when delaying flowering to avoid grain mold is the desired target (Thakur et al., 2006). The result showed the existence of genetic resources to improve these traits depending on breeding target. These parents provide an opportunity to generate more desirable transgressive segregants for traits of interest under diverse environments, if used in breeding program (Kanawade et al., 2001). The estimates of SCA provide important information about hybrid performance as related to its parents, showing the importance of non-additive interaction due to large or minor gene effects in specific hybrid combination (Kenga et al., 2004). The 
significant negative or positive SCA found for many crosses in this study could be used in breeding programmes. For days to flowering and plant height, both negative and positive significant SCA effects could be used depending on the targeted environments and farmer's preferences. For grain weight and panicle length, highly significant positive SCA crosses are expected to increase grain yield. The best combinations were AVG-1 x K31.3 and AVG-1 x Tg148 for the same such traits. Only accession K37 with good GCA had significant positive SCA, with both female lines AVG-1 and CE310-1A, which had contrasted GCA. This implies that accession K37 could be used as a suitable parent to develop not only superior hybrids but also improve inbred lines. Per se performance and combining ability in predicting hybrid superiority

A significant and high correlation was observed for all traits between general combining ability and per se performance of parents. This means that parents' per se performance gives an idea on their general combining ability, and thus constitutes a good predictor of their performance in cross. For grain weight, strong correlations were observed between hybrid superiority and specific combining ability $(r=0.69)$, and general combining ability $(\mathrm{r}=0.65)$; and between hybrid superiority and per se performance of hybrid $(r=0.94)$. Similar findings were reported in previous studies (Premalatha et al. 2006; Rajendrakumar, 2015). This implies that parents of superior hybrids could be identified based on their combining ability among high yielding accessions. This will reduce the number of testcrosses to be carried out on field evaluation. However, hybrid per se performance may be the paramount criteria.

Suitable heterotic grouping method. The genetic distance based on SNPs markers structured the population into seven classes, with respect to geographic origin and racial group (Fig. 1). This result indicates that local adaptation alleles are the most discriminants ones in genetic population structure. This population pattern is in agreement with Morris et $a l$. (2013) who found a population structure with respect to geographic origin and morphological type in 971 worldwide accessions, using 265,000 single nucleotide polymorphisms (SNPs).

Combining ability based methods classified sorghum accessions into four groups (Table 5). The HGCAMT method provides information related to plant performance and general combining ability of multiple traits as showed by correlation between per se performance and general combining ability (Fig. 2). The SCA effects of grain weight distinguished parents generating good hybrid with one or both female parents from other accessions. This method identified Sn32, Tg136, K37, K31.3, Ni331 and ML110 with both female parents as the best combinations for superior hybrids production. The SCA effects of grain weight method could allow identification of the best combination for hybrid breeding programs. This is in agreement with Cruz and Regazzi (1994), who suggested examining GCA effect of each parent when the objective is to develop superior genotypes; while specific combining ability (SCA) effects when looking for hybrid performance. The HSGCA method distinguished genotypes with good GCA and SCA with both testers (Fig. 2). There was similarity between the classifications based on the four grouping methods. Genotypes Sn69, Sn35 and Sn125 were classified together by SNPs based genetic distance, SCA effect and HGCAMT. The three genotypes had a detrimental effect on grain yield when crossed. Similarly, K31.3 and K37 were classified into the same group by SCA effects of grain weight, HGCAMT and genetic distance methods. The two genotypes had good GCA for grain weight. This result strengthens the consistency of heterotic grouping methods used in this study. The suitable heterotic grouping method is the one that allow the identification of superior hybrids. 
Accordingly, our study identified HSGCA as the best heterotic grouping method that distinguished genotypes whose hybrids yielded a $15 \%$ advantage over mid-parents.

\section{CONCLUSION}

Our study highlighted heterotic responses among West African sorghum accessions for traits studied indicating the existence of favourable alleles for breeding programmes. Specific environment based improvement may allow good progress rather than large adaptation. The dominance gene effect was predominant in the inheritance of these traits suggesting direct selection methods. Parents K31.3, K37 and Ni331 were the best combiners for grain weight providing opportunity for breeders to improve grain yield under diverse environments. AVG-1 x K31.3 and AVG-1 x $\operatorname{Tg} 148$ were found to be the best combinations for superior hybrids. The HSGCA method was the suitable in superior hybrid prediction. These combining ability based heterotic grouping information could be useful for sorghum breeders using local adapted accessions to identify best parents for superior hybrids development in West Africa.

\section{ACKNOWLEDGEMENT}

The authors thank the West Africa Agricultural Productivity Programme (WAAPP-Togo) for providing the Ph.D. scholarship for the first author. They are also thankful to Dr. Kebede Muleta for reviewing this paper. The authors thank the sorghum breeding team and CERAAS' technicians of National Centre of agricultural Research (CNRA) of Bambey for helping in planning and conducting the experiment. This study is made possible by the support of the American People provided to the Feed the Future Innovation Lab for Collaborative Research on Sorghum and Millet through the United States Agency for International Development (USAID). The contents are the sole responsibility of the authors and do not necessarily reflect the views of USAID or the United States Government. Program activities are funded by the United States Agency for International Development (USAID) under Cooperative Agreement No. AID-OAA-A-13-00047.

\section{REFERENCES}

Akinwale, R.O., Badu-apraku, B., Fakorede, M.A.B. and Vroh-bi, I. 2014. Heterotic grouping of tropical early-maturing maize inbred lines based on combining ability in Striga-infested and Striga-free environments and the use of SSR markers for genotyping. Field Crop Research 156:48-62. doi:10.1016/j.fcr.2013.10.015

Badu-Apraku, B., Oyekunle, M., Fakorede, M.A.B., Vroh, I., Akinwale, R.O. and Aderounmu, M. 2013. Combining ability, heterotic patterns and genetic diversity of extra-early yellow inbreds under contrasting environments. Euphytica 192: 413-433. doi:10.1007/s10681-013-0876-4

Barro-Kondombo, C.P., Kirsten, V.B., Jacques, C., Fabrice, S. and Jean-Didier, 2008. Variabilité phénotypique des sorghos locaux de deux régions du Burkina Faso/ : la Boucle du Mou- houn et le Centre-Ouest. John Libbey Eurotext 17:73-256.

Beil, G.M. and Atkins, R.E. 1967. Estimates of general and specific combining ability in $F_{1}$ hybrids for grain yield and its components in grain sorghums Sorghum vulgare Pers.1. Crop Science 7: 225-228. doi:10.2135/cropsci1967.0011183X $000700030016 x$

Billot, C., Ramu, P., Bouchet, S., Chantereau, J., Deu, M., Rivallan, R., Li, Y., Lu, P., Gardes, L., Noyer, J., Wang, T., Folkertsma, R.T., Arnaud, E., Upadhyaya, H.D., Glaszmann, C. and Hash, C.T. 2013. Massive sorghum collection genotyped with SSR markers to enhance use of global genetic resources 8:1-16. doi:10.1371/ journal.pone.0059714 
Camara, Y., Bantilan, M. and Ndjeunga, J. 2006. Impacts of sorghum and millet research in West and Central Africa (WCA): A synthesis and lessons learnt. International Crops Research Institute for the Semi-Arid Tropics. 22pp.

Cox, D.J. and Frey, K.J. 1984. Combining ability and the selection of parents for interspecific oat matings1. Crop Science 24:963-967. doi:10.2135/cropsci1984. 0011183X002400050033x

Cruz, C.D. and Regazzi, A.J. 1994. Modelos biométricos aplicados ao melhoramento genético. Viçosa. pp. 287-313.

Deu, M., Rattunde, H.F.W. and Jacques, C., 2006. A global view of genetic diversity in cultivated sorghums using a core collection. Genome 49:168-180.

Elshire, R.J., Glaubitz, J.C., Sun, Q., Poland, J.A., Kawamoto, K., Buckler, E.S. and Mitchell, S.E. 2011. A robust, simple genotyping-by-sequencing (GBS) approach for high diversity species 6:1-10. doi:10.1371/journal.pone.0019379

Fan, X.M., Zhang, Y.M., Yao, W.H., Chen, H.M., Tan, J., Xu, C.X., Han, X.L., Luo, L.M. and Kang, M.S. 2009. Classifying maize inbred lines into heterotic groups using a factorial mating design. Agronomy Journal 101:106-112. doi:10.2134/ agronj2008.0217

Frost, R.L., Xi, A.Y. and He, H. 2007. Modification of the surfaces of Wyoming montmorillonite by the cationic surfactants alkyl trimethyl, dialkyl dimethyl and trialkyl methyl ammonium bromides. Journal of Colloid and Interface Science 305:150158.

Glaubitz, J.C., Casstevens, T.M., Lu, F., Harriman, J., Elshire, R.J., Sun, Q. and Buckler, E.S. 2014. TASSEL-GBS/: A high capacity genotyping by sequencing analysis pipeline. PLoS One 9:1-11. doi:10.1371/ journal.pone.0090346

IBPGR/ICRISAT, 1993. Key access and utilization descriptors for sorghum genetic resources. International Sorghum and Millets Newsletter 47:35-41.

Kanawade, D.G., Deshmukh, R.B., Kute, N.S., Patil, J.V. and Dhonde, S.R. 2001. Combining ability studies in sorghum commercial exploitation of heterosis. The mean squares due to female. Indian Journal of Agricultural Research 35:56-59.

Kante, M., Rattunde, H.F.W., Leiser, W.L., Nebié, B., Diallo, B., Touré, A.O., Weltzien, E. and Haussmann, B.I.G. 2017. Can tall guinea-race sorghum hybrids deliver yield advantage to smallholder farmers in West and Central Africa/ ? Crop Science 10:110. doi:10.2135/cropsci2016.09.0765

Kempthorne, O. 1957. An introduction to genetic statistics, John Wiley (Ed.). National Academy of Sciences: National Research Council. National Academy of Sciences-National Research Council, New York.

Kenga, R., Alabi, S.O. and Gupta, S.C. 2004. Combining ability studies in tropical sorghum (Sorghum bicolor ( L .) Moench) Field Crop Research 88:251-260. doi:10.1016/j.fcr.2004.01.002

Kenga, R., Alabi, S.O. and Gupta, S.C. 2005. Heterosis and combining ability for grain yield and its components in induced sorghum mutants. African Crop Science Journal 13:143-152.

Kirby, J.S. and Atkins, R.E. 1968. Heterotic response for vegetative and mature plant characters in grain sorghum (Sorghum bicolor (L.) Moench). Crop Science 8:335339. doi:10.2135/cropsci1968.0011183 $\mathrm{X} 000800030022 \mathrm{x}$

Melchinger, A.E. and Gumber, R.K. 1998. Overview of heterosis and heterotic groups in agronomic crops. In: Concepts and breeding of heterosis in crop plants. CSSA Special Publication SV - 25. Crop Science Society of America, Madison, WI, USA. pp. 29-44. doi:10.2135/cssaspecpub25.c3

Melchinger, A. 1999. Genetic diversity and heterosis. In: The genetics and exploitation of heterosis in crops. Coors, J.G. and 
Pandey, S. (Eds.). Madison, WI, USA. pp. 99-118. doi:10.2134/1999.geneticsand exploitation.c10

Mindaye, T.T., Mace, E.S., Godwin, I.D. and Jordan, D.R. 2016. Heterosis in locally adapted sorghum genotypes and potential of hybrids for increased productivity in contrasting environments in Ethiopia. Crop Journal 4:479-489. doi:10.1016/j.cj.2016. 06.020

Morris, G.P., Ramu, P., Deshpande, S.P., Hash, C.T., Shah, T., Upadhyaya, H.D., RieraLizarazu, O., Brown, P.J., Acharya, C.B., Mitchell, S.E., Harriman, J., Glaubitz, J.C., Buckler, E.S. and Kresovich, S. 2013. Population genomic and genome-wide association studies of agroclimatic traits in sorghum. PNAS 110:453-458.

Murty, D.S. 2002. Hybrid sorghum in West Africa. In: West African Hybrid Sorghum and Pearl Millet Seed Workshop. pp. 9193.

Olembo, K., M'mboyi, F. and Kiplagat, S. 2010. Sorghum breeding in Sub-Saharan Africa: The success stories. African Biotechnology. Stakeholders Forum. 37pp.

Ouédraogo, S. 2005. Intensification de l' agriculture dans le Plateau Central du Burkina Faso/: Une analyse des possibilités à partir des nouvelles technologies s.n. University of groningen, Netherlands. doi:http://hdl.handle.net/(...)84-b382cc28b11fa1a7

Parviz, F., Abazar, R., Javad, M.R. and Derera, J. 2016. Principles and utilization of combining ability in plant. Biometrics and Biostatistics International Journal 4:1-24. doi:10.15406/bbij.2016.04.00085

Premalatha, N., Kumaravadivel, N. and Veerabadhiran, P. 2006. Heterosis and combining ability for grain yield and its components in sorghum (Sorghum bicolor ( L .) Moench ]. Indian Journal of Genetics and Plant Breeding 66:123-126.

Pswarayi, A. and Vivek, B.S. 2004. Combining ability amongst CIMMYT's early maturing maize (Zea mays L.) germplasm under stress and non-stress conditions and identification of testers. Retrieved: September 12, 2005 from http: www.cropscience.org.au/icsc204/ poster/ 3/4/5/845_vivekb.htm.

Rajendrakumar, P. 2015. Heterosis prediction using DNA markers. In: Sorghum molecular breeding. Springer. pp. 101-114.

Rosyara, U.R. 2014. Plantbreeding: Analysis and visualization of data from plant breeding and genetics experiments. https://r-forge.rproject.org/projects/plantbreeding/

Sagnard, F., Monique, D., Dembélé, D., Leblois, R., Lassana, T., Diakite, M., Caroline, C., Michel, V., Sophie, B., Malle, Y., Togola, S. and Traoré, P.C.S. 2011. Genetic diversity, structure, gene flow and evolutionary relationships within the Sorghum bicolor wild-weedy-crop complex in a western African region. Theoretical and Apply Genetics 123:12311246. doi:10.1007/s00122-011-1662-0

Sawadogo, N., Nebie, B., Kiebre, M., Kando, P.B., Nanema, R.K., Traore, R.E., Naoura, G., Sawadogo, M. and Zongo, J. 2014. Caractérisation agromorphologique des sorghos à grains sucrés (Sorghum bicolor ( L.) Moench) du Burkina Faso 8:21832197.

Singh, R. and Chaudhary, B. 1977. Biometrical methods in quantitative genetic analysis, Kalyani Publishers. Kalyani Publishers, New Delhi, India.

Singh, R.K. and Chaudhary, B.D. 1985. Biometrical Methods in Quantitative Genetics Analysis. Kalyani Publishers. New Delhi, India.

Stephens, J.C. and Holland, P.F. 1954. Cytoplasmic male sterility for hybrid sorghum seed production. Agronomy Journal 46:20-23.

Taylor, J.R.N. 2003. Importance of sorghum in Africa. In Proceedings of AFRIPRO Workshop on the proteins of sorghum and millets: Enhancing nutritional and functional properties for Africa. Australian Journal of Experimental Agriculture 9:193. doi:10.1071/EA9930193 
Thakur, R.P., Reddy, B.V.S., Indira, S., Rao, of the economic impact of sorghum and V.P., Navi, S.S., Yang, X.B. and Ramesh, S. 2006. Sorghum grain mold. Information Bulletin No. 72. International Crops Research Institute for the Semi-Arid Tropics. Patancheru 502324, Andhra Pradesh, India: 32 pp. ISBN 92-9066-4886. Order code IBE 072.

Yapi, A.M., Kergna, A.O., Debrah, S.K., Sidibe, A. and Sanogo, O. 2000. Analysis millet research in Mali. International Crops Research Institute for the Semi-Arid Tropics 8:64.

Zongo, J.D., Gouyon, P.H., Sarr, A. and Sandmeier, M. 2005. Genetic diversity and phylogenic relations among Sahelian sorghum accessions. Genetic Resources and Crop Evolution 52:869-878. doi:10.1007/s10722-003-6091-8 